\title{
Foreword by Professor Gab Kovacs
}

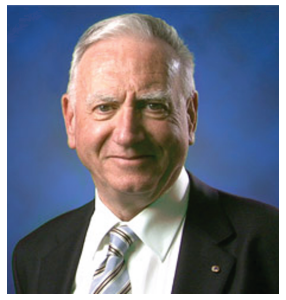

It gives me great pleasure to write the Editorial to the first edition of Fertility \& Reproduction ( $F$ \& $R$ ): The Official Journal of ASPIRE.

When I was asked if I would be interested in taking on the role of Editorin-Chief of the official journal of our Organization, I was honored and delighted. It is a great opportunity to be able to launch a new journal, especially one that is designed for the $21^{\text {st }}$ Century, being published electronically, and providing free access to all readers. The journal is also aimed at showcasing some of the research originating from the Asia-Pacific region. Our "role models" are two of the world's best reproductive journals, Fertility and Sterility and Human Reproduction, that is why we have chosen the name Fertility \& Reproduction.

We have established an expert Editorial Board, with every previous President of ASPIRE agreeing to be an Associate Editor. This learned group, together with experts around the world, will take on the role of Associate Editor, responsible for distributing the submitted papers (blinded) to referees of their choosing. Taking into account reviewers' comments, the Associate Editor will then make a final recommendation on whether the paper should be published. As with other journals, sometimes modifications will be recommended and their revised versions reconsidered.
I have also introduced an innovation, where although the official language of our journal is English, the abstract will also be published in the natural language of the authors. This will enable researchers who publish in our journal to circulate at least the abstract to their local colleagues.

We aim to raise the profile of $F \& R$ as much as we can by achieving PubMed listing as soon as possible.

We hope that you and your colleagues will submit your research papers for consideration for publication to $F \& R$.

The establishment of the Journal would not have been possible without the support of the ASPIRE Board, especially our Secretary General Professor P. C. Wong, and the administrative team of Ms. Jing Qi Hoa and Ms. Yanny Wu, to whom I express my thanks.

Happy Reading!

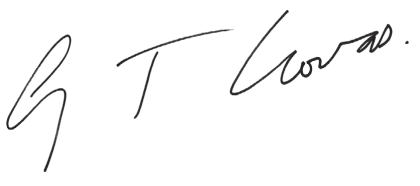

Professor Gab Kovacs AM

Editor-in-Chief

Fertility \& Reproduction

(c) 2019 by the Asia Pacific Initiative on Reproduction (ASPIRE) and World Scientific Publishing Co. Pte. Ltd. 2 Open Access article under the CC BY-NC-ND license (http://creativecommons.org/licenses/by-nc-nd/4.0/). 